\title{
Ovarian cancer cells direct monocyte differentiation through a non-canonical pathway
}

Kaitlin C. Fogg ${ }^{1 \dagger}$, Andrew E. Miller ${ }^{1 \dagger}$, Ying Li ${ }^{2}$, Will Flanigan', Alyssa Walker ${ }^{1}$, Andrea O'Shea ${ }^{3}$, Christina Kendziorski ${ }^{2}$ and Pamela K. Kreeger $r^{1,3,4,5^{*}}$

\begin{abstract}
Background: Alternatively-activated macrophages (AAMs), an anti-inflammatory macrophage subpopulation, have been implicated in the progression of high grade serous ovarian carcinoma (HGSOC). Increased levels of AAMs are correlated with poor HGSOC survival rates, and AAMs increase the attachment and spread of HGSOC cells in vitro. However, the mechanism by which monocytes in the HGSOC tumor microenvironment are differentiated and polarized to AAMs remains unknown.

Methods: Using an in vitro co-culture device, we cultured naïve, primary human monocytes with a panel of five HGSOC cell lines over the course of 7 days. An empirical Bayesian statistical method, EBSeq, was used to couple RNA-seq with observed monocyte-derived cell phenotype to explore which HGSOC-derived soluble factors supported differentiation to CD68+ macrophages and subsequent polarization towards CD163+ AAMs. Pathways of interest were interrogated using small molecule inhibitors, neutralizing antibodies, and CRISPR knockout cell lines.

Results: HGSOC cell lines displayed a wide range of abilities to generate AAMs from naïve monocytes. Much of this variation appeared to result from differential ability to generate CD68+ macrophages, as most CD68+ cells were also CD163+. Differences in tumor cell potential to generate macrophages was not due to a MCSF-dependent mechanism, nor variance in established pro-AAM factors. TGFa was implicated as a potential signaling molecule produced by tumor cells that could induce macrophage differentiation, which was validated using a CRISPR knockout of TGFA in the OVCAR5 cell line.
\end{abstract}

Conclusions: HGSOC production of TGFa drives monocytes to differentiate into macrophages, representing a central arm of the mechanism by which AAMs are generated in the tumor microenvironment.

Keywords: M2 macrophage, Tumor associated macrophage, EGFR, mAb225

\footnotetext{
* Correspondence: kreeger@wisc.edu

${ }^{\dagger}$ Kaitlin C. Fogg and Andrew E. Miller contributed equally to this work.

'Department of Biomedical Engineering, University of Wisconsin-Madison,

1111 Highland Ave, WIMR 4553, Madison, WI 53705, USA

${ }^{3}$ Department of Obstetrics and Gynecology, University of Wisconsin School

of Medicine and Public Health, Madison, WI, USA

Full list of author information is available at the end of the article
}

(c) The Author(s). 2020 Open Access This article is licensed under a Creative Commons Attribution 4.0 International License, which permits use, sharing, adaptation, distribution and reproduction in any medium or format, as long as you give appropriate credit to the original author(s) and the source, provide a link to the Creative Commons licence, and indicate if changes were made. The images or other third party material in this article are included in the article's Creative Commons licence, unless indicated otherwise in a credit line to the material. If material is not included in the article's Creative Commons licence and your intended use is not permitted by statutory regulation or exceeds the permitted use, you will need to obtain permission directly from the copyright holder. To view a copy of this licence, visit http://creativecommons.org/licenses/by/4.0/ The Creative Commons Public Domain Dedication waiver (http://creativecommons.org/publicdomain/zero/1.0/) applies to the data made available in this article, unless otherwise stated in a credit line to the data. 


\section{Background}

High grade serous ovarian carcinoma (HGSOC) is the deadliest gynecological malignancy, accounting for $70 \%$ of all ovarian cancer related mortalities [1]. The late-stage of diagnosis, coupled with extensive metastasis to secondary sites, renders the five-year survival rate of HGSOC at less than $30 \%$ [2]. The tumor microenvironment of HGSOC is highly complex, comprising multiple different types of cells as well as a diverse range of chemical and physical cues $[3,4]$. A key cell type present in most solid tumors is a macrophage, accounting for up to $40 \%$ of tumor mass; increased macrophage numbers correlate with poor patient outcomes across many cancer types [5]. Macrophages are vital members of the innate immune system, playing roles in both initiation and resolution of the inflammatory response [6]. This duality of function is primarily due to the plasticity of macrophages, which exist along a spectrum ranging from classically-activated macrophages (CAMs, pro-inflammatory) to alternativelyactivated macrophages (AAMs, anti-inflammatory). Both CAMs and AAMs are derived from monocytes, which infiltrate wound beds or tumor microenvironments in response to secretion of chemokine ligand 2 (CCL2, also known as MCP-1). Once monocytes differentiate to macrophages, they continuously interpret microenvironmental cues and respond by adjusting their polarization, altering their position along the inflammatory spectrum accordingly [7-9].

Many tumor-associated macrophages have a protumor, anti-inflammatory phenotype comparable to alternatively-activated macrophages $[10,11]$. In HGSOC, elevated levels of macrophages with this alternative polarization in the ascites fluid correlate with poor patient survival [12-14]. In vivo, a resident population of omental CD163+ macrophages has been shown to be essential for metastatic spread in a mouse model of ovarian cancer [15]. Using in vitro models of HGSOC, we have previously demonstrated that AAMs secrete soluble factors such as MIP-1 $\beta$, HB-EGF, and leptin, resulting in increased ovarian cancer cell adhesion, proliferation, and spreading, respectively [16-18]. In these studies, AAMs were generated by differentiating naïve monocytes into macrophages with MCSF and then polarizing towards the alternative phenotype through IL-4 and IL-13 treatment, resulting in a cell population that is CD68+, CD163+ [19]. However, while the pro-tumorigenic influence of AAMs on ovarian cancer progression has been established, the reciprocal question of the role of the tumor cell in the generation of AAMs from monocytes has not been well characterized in HGSOC.

Identifying mechanisms by which monocytes are differentiated to macrophages, polarized towards an AAM phenotype, and then stabilized in that phenotype could potentially identify new targets to control cancer progression. Prior studies have demonstrated that different tumor subtypes utilized distinct cancer-macrophage signaling axes [10]; thus, we hypothesized that ovarian cancer cells may produce a unique subset of soluble factors to regulate this process. To explore this hypothesis, we modified an in vitro co-culture model previously developed in our lab [20] to include naïve primary human monocytes and five human ovarian cancer cell lines. We then used this system to examine the macrophage differentiation/polarization potential of ovarian cancer cell lines. Based on our observations and the results of RNAseq of the selected cancer cell lines, we then use bioinformatics approaches and experimental follow-up to identify potential mechanisms involved in ovarian cancer cell direction of macrophage differentiation.

\section{Methods}

Unless stated, all reagents were purchased from ThermoFisher (Waltham, MA).

\section{Monocyte isolation and HGSOC culture}

Whole blood from healthy females (age 18-55) was purchased from Zen Bio (Durham, NC). Monocytes were enriched using RosetteSep Human Monocyte Enrichment Cocktail in combination with SepMate $50 \mathrm{~mL}$ tubes according to the manufacturer's instructions (STEMCELL Technologies, Seattle, WA). Human HGSOC cell lines OV90 and OVCAR3 were purchased from ATCC (Manassas, Virginia), OVCA432 and OVCAR5 were obtained from Dr. R. Bast (MD Anderson Cancer Center; Houston, TX, USA), and OVCAR4 were obtained from the NCI Tumor Repository (Frederick, MD). All ovarian cancer cell lines were maintained in ovarian cancer media $(1: 1(\mathrm{v} / \mathrm{v})$ ratio of MCDB105: Medium199 (Corning, Corning, NY) supplemented with 1\% penicillin/streptomycin) with $15 \%$ heat-inactivated fetal bovine serum prior to co-culture.

\section{In vitro micro-culture device}

For all co-culture studies, an in vitro micro-culture device was used that allows for the examination of paracrine signaling in a controlled environment [20]. The microdevice was constructed by placing an oval PDMS ring $(11 \times 17 \times 0.5 \mathrm{~mm})$ in a well of a 24 well plate. Freshly isolated monocytes were seeded in each well at a concentration of 400,000 cells per well in $40 \mu \mathrm{L}$ of AIMV media supplemented with $1 \%$ penicillin-streptomycin. Glass coverslips $(9 \times 9 \mathrm{~mm})$ were coated with $8 \mu \mathrm{g} / \mathrm{mL}$ collagen I (Sigma, St. Louis, MO) in PBS overnight, after which point ovarian cancer cells were dissociated with trypsin and seeded on the coverslips at a concentration of 25,000 cells per coverslip in ovarian cancer media.

Co-culture was initiated by inverting the ovarian cancer-containing coverslip and placing it on top of the PDMS ring that contained either naïve monocytes or 
AIMV alone. Every 2 days a new HGSOC coverslip was added to the co-culture device and the AIMV media was replaced, and $4 \mu \mathrm{L}$ of AIMV media was added to each device on alternate days to counteract evaporation. For some experiments, HGSOC cells were cultured on coverslips in the device without monocytes. AAM control monocultures were generated as previously described [16]. Briefly, monocytes were differentiated into macrophages over the course of 5 days in AIMV media supplemented with $1 \%$ penicillin-streptomycin and $20 \mathrm{ng} / \mathrm{mL}$ MCSF. Macrophages were subsequently polarized to AAMs over the course of 2 days in AIMV media supplemented with $1 \%$ penicillin-streptomycin and $2 \mathrm{ng} / \mathrm{mL}$ IL-4 and IL-13. To generate CAMs monocytes were differentiated into macrophages over the course of 5 days in AIMV media supplemented with $1 \%$ penicillinstreptomycin and $20 \mathrm{ng} / \mathrm{mL}$ GMCSF, then polarized to CAMs by culturing the cells in AIMV media supplemented with $1 \%$ penicillin-streptomycin, $20 \mathrm{ng} / \mathrm{mL}$ IFN $\gamma$ and $100 \mathrm{ng} / \mathrm{mL}$ lipopolysaccharide (LPS) [21].

\section{Immunocytochemistry}

Following 7 days of co-culture, cancer cell coverslips were removed from the top of the PDMS ring and the monocyte derived cells (MDCs) at the bottom of the microdevice were fixed for 30 min using $4 \%$ paraformaldehyde. MDCs were rinsed with $0.1 \%$ BSA in PBS then permeabilized and blocked in buffer containing $0.3 \%$ Triton X-100 and 1\% normal goat serum in PBS for 45 min at room temperature. Cells were then incubated with primary antibodies diluted in dilution buffer containing $1 \%$ BSA, $0.3 \%$ Triton-X, $1 \%$ normal goat serum, and $0.01 \%$ sodium azide for $2 \mathrm{~h}$ at $25^{\circ} \mathrm{C}$ [anti-CD68 (1: 200, ab213363, Abcam, Eugene, OR), anti-CD163 (1:100, ab182422, Abcam)]. After rinsing with PBS, all cells were incubated with secondary antibody diluted in the same dilution buffer as the primary antibodies (1:500 goat anti-rabbit IgG Alexa Fluor 488) for $1 \mathrm{~h}$ at room temperature protected from light, then counterstained with Hoescht 33,258 for 5 min (1:1000). All images were obtained using a Zeiss Axio Observer.Z1 inverted microscope with an AxioCam 506 mono camera, PlanApochromat $20 \times 0.16-\mathrm{NA}$ air objective, and Zen 2 software (Zeiss). ImageJ software (NIH) was used to quantify CD68+ and CD163+ counts per field of view, and percent CD68 and CD163 were calculated as the ratio of CD68+ or CD163+ counts to total cell counts from the Hoechst signal.

\section{RT-qPCR analysis of gene expression}

RNA was isolated from HGSOC cells in monoculture or co-culture at day 7 using the RNeasy Mini Kit (Qiagen, Germantown, Maryland) according to the manufacturer's instructions. cDNA was synthesized and amplified using the $\mathrm{RT}^{2}$ PreAMP cDNA Synthesis Kit, then assayed using a custom $\mathrm{RT}^{2}$ Profiler PCR array for IL4, IL10, CSF1, CCL2, IL13, TNF, and IFNG (Qiagen) in a CFX real-time PCR machine (Bio-Rad, Pleasanton, CA) for a total of 40 cycles, using Qiagen's Data Analysis Center for analysis. Data are expressed as fold change, with \pm 2 -fold set as the threshold for significance.

\section{Bioplex analysis of cytokine profiles}

Conditioned media was collected from HGSOC cells in monoculture or co-culture at day 7. Media samples were centrifuged at $10,000 \mathrm{~g}$ for $10 \mathrm{~min}$, and the supernatant was frozen at $-80^{\circ} \mathrm{C}$ until assayed. Quantification of cytokines IL-15, VEGF, IL-9, PDGF-BB, IL-5, MIP-1 $\beta$, RANTES, GCSF, IL-12, IL-13, IL-7, IL 17, IL-1ra, bFGF within the conditioned media was performed using a Human Cytokine Th1/Th2 Assay (Bio-Rad). Protein quantification was performed using a MAGPIX instrument (Luminex Corporation, Madison, WI) and assessed using xPONENT for MAGPIX software.

\section{RNA-seq}

RNA was isolated from four biological replicates each of the five HGSOC cell lines using the RNeasy Mini Kit (Qiagen) according to the manufacturer's instructions. RNA quality was assessed at the University of Wisconsin Biotechnology Center using an Agilent RNA PicoChip and sample libraries were prepared using poly-A selection with TruSeq Stranded mRNA Library Prep Kit (Illumina, Madison, WI) according to manufacturer's instructions. Prepared libraries were sequenced on an Illumina HiSeq 2500 targeting a read depth of 25 million reads per sample by the University of Wisconsin Bioinformatics Resource Center.

\section{Data processing and differential expression analysis}

Paired end sequencing $(2 \times 125$ bases $)$ was performed on each sample in one lane of a Illumina HiSeq 2500 sequencer. Reads were mapped back to the genome using the short read aligner Bowtie followed by RSEM [22] to estimate gene expression. All samples passed quality-control and were used in downstream analyses, which were carried out in $\mathrm{R}$ ( $\mathrm{R}$ Development Core Team, 2012). Specific software packages were obtained from Bioconductor, an online suite of tools for the analysis of genomic data [23] unless otherwise noted. DESeq2 [24] was used to visualize the individual gene expression contrasts between the OV90 cell line and OVCAR3, OVCAR4, OVCAR5, and OVCA432 cell lines, as well as to perform principal component analysis. Heatmaps of Pearson correlations between all samples were synthesized and visualized with the package pheatmap v1.0.12 [25]. Differential expression data 
from DESeq2 outputs were visualized in Venn diagram form using the Limma package [26]

EBSeq [22] was applied to identify differentially expressed genes. To determine if a gene is differentially expressed, we considered six potential patterns of expression (P1-P6, below) across our five cell lines. For each gene, the normalized read counts in condition 1 ( $\mu 1$ : OV90) were compared with that in condition $2(\mu 2$ : OVCAR4), condition 3 ( $\mu 3$ : OVCAR3), condition 4 ( $\mu 4$ : OVCAR5) and condition 5 ( $\mu 5$ : OVCA432).

$$
\begin{aligned}
& P 1: \mu 1 \neq \mu 2 \neq \mu 3 \neq \mu 4 \neq \mu 5 \\
& P 2: \mu 1=\mu 2 \neq \mu 3 \neq \mu 4 \neq \mu 5 \\
& P 3: \mu 1 \neq \mu 2=\mu 3 \neq \mu 4 \neq \mu 5 \\
& P 4: \mu 1 \neq \mu 2 \neq \mu 3=\mu 4 \neq \mu 5 \\
& P 5: \mu 1 \neq \mu 2 \neq \mu 3 \neq \mu 4=\mu 5 \\
& P 6: \mu 1=\mu 2=\mu 3 \neq \mu 4=\mu 5
\end{aligned}
$$

EBSeq calculates the posterior probability of a gene being in each expression pattern. False discovery rates were controlled within EBSeq at 5\%. To further sort the genes into those patterns that correlated with observed pro-AAM potential, gene expression was further evaluated for those that adhered to one of the two criteria:

$$
\begin{aligned}
& C 1: \mu 1 \leq \mu 2 \leq \mu 3 \leq \mu 4 \leq \mu 5 \\
& C 2: \mu 1 \leq \mu 2 \leq \mu 3 \leq \mu 4 \geq \mu 5
\end{aligned}
$$

This resulted in two final expression patterns that mimicked the number of CD68+ and CD163+ cells in co-culture (Supplemental Figure 1).

\section{Inhibition of candidate factor signaling}

Inhibition of signaling molecules identified using RNAseq was performed by supplementing AIM-V media with small molecule inhibitors or antibodies in OVCAR5 cocultures. FAM3C was inhibited with $10 \mu \mathrm{M}$ DAPT [27], a $\gamma$-secretase inhibitor that blocks FAM3C signaling pathway activation; LIF and TGFo downstream signaling was inhibited using $5 \mu \mathrm{M}$ galiellalactone $(\mathrm{GL})$, a selective STAT3 inhibitor [28]; AMH signaling was inhibited via the addition of $120 \mathrm{ng} / \mathrm{mL}$ anti-AMHR2 according to manufacturer's instructions (Abcam); the receptor for TGF $\alpha$ and epigen (EGFR) was inhibited with $10 \mu \mathrm{g} / \mathrm{mL}$ mAb225 (Abcam) [17]. The vehicle control medium was AIMV supplemented with $10 \mu \mathrm{g} / \mathrm{mL}$ IgG1 isotype control [17]. 1X concentrations of inhibitors were replaced in $40 \mu \mathrm{L}$ AIMV media every other day, and 10X concentrations of inhibitors were added in $4 \mu \mathrm{L}$ AIMV media on alternate days to counteract evaporation.

\section{CRISPR mediated knockout of TGFA and LIF in OVCAR5} cells

CRISPR/Cas9 was used to knock out TGFA or LIF in OVCAR 5 cells. Briefly, a 20 oligonucleotide (oligo) guide RNA (gRNA) targeting either the TGFA or LIF loci was designed using $\mathrm{CHOPCHOP}$ to minimize off-target binding [29]. The gRNA sequences (TGFA gRNA oligos: FWD 5'-CACCGGTGCACCAACGTACCCAGAA-3', REV 5'-AAACTTCTGGGTACGTTGGTGCACC-3'; LIF gRNA oligos: FWD 5'-CACCGGCGGGAAG TCCGTCACGTTG-3', REV 5'-AAACCAACGTGAC GGACTTCCCGCC-3') were flanked with the NGG PAM sequence on the $3^{\prime}$ end and were synthesized by Integrated DNA Technologies (Coralville, IA). lentiCRISPR v2 was a gift from Feng Zhang (Addgene plasmid \#52961; http://n2t.net/addgene:52961; RRID: Addgene_52,961); this one vector system delivers hSpCas9 and chimeric gRNA expression cassettes [30]. The lentiCRISPRv2 vector was dephosphorylated and digested with BsmBI restriction enzyme and subsequently gel-purified. The forward and reverse gRNA oligos were phosphorylated, annealed, and ligated into the cut vector. One Shot Stbl3 Chemically Competent E. coli (C737303, Invitrogen) were transformed with the TGFA or LIF lentiCRISPRv2 plasmid and grown in LB with $100 \mu \mathrm{g} / \mathrm{mL}$ ampicillin for selection and expansion. HEK293T cells were co-transfected with packaging plasmids from the Lenti-vpak Lentiviral Packaging Kit (TR30037, Origene) and either the TGFA or LIF lentiCRISPRv2 plasmid, using MegaTran 1.0 as the transfection agent. After 48 and $72 \mathrm{~h}$ of incubation, viral batches were collected and combined for each gene target. This viral supernatant was used to deliver the TGFA- or LIFtargeting CRISPR/Cas9 system into the OVCAR5 cell line at a 2:3 virus to ovarian cancer media volume ratio. Polybrene was added at $8 \mu \mathrm{g} / \mathrm{mL}$, and the plate was centrifuged at $165 \mathrm{~g}$ for $2 \mathrm{~h}$ to aid transduction. After incubation for $48 \mathrm{~h}, 10 \mu \mathrm{g} / \mathrm{mL}$ puromycin (A1113803, Invitrogen) was added for an additional $48 \mathrm{~h}$ for selection. To confirm successful cutting at the TGFA or LIF loci, genomic DNA was isolated for Sanger Sequencing with the following primers (TGFA FWD 5'-TGTCATGAACACATGTGCTGCC-3', REV 5'-TTCTGGTGCT GATGGAAGGAGG-3'; LIF FWD 5'-GGCTAGACACCGAGTTTTCCCT-3', REV 5'- CCTGAGATCC CTCGGTTCACAG-3'). Sequencing was performed by the UW-Madison Biotechnology Center. The mutant TGFA and LIF sequences were aligned to WT TGFA and WT LIF sequences respectively, using Tracking of Indels by DEcomposition (TIDE) software [31]. These cell lines were termed OVCAR5 $5^{\mathrm{TGFA-l}-}$ and OVCAR $5^{\mathrm{LIF-}-1}$. To confirm a knockout on the protein level, an ELISA for TGF $\alpha$ and LIF (R\&D Systems, Minneapolis, MN) was performed according to manufacturer's instructions. 


\section{Statistical analysis}

Data are presented as mean \pm standard deviation of the mean. Statistical analysis (one-way ANOVA, two-way ANOVA, or t-tests when appropriate) was performed in Prism 7 software (Graph-Pad, San Diego, CA).

\section{Results}

HGSOC cell lines promote primary monocyte differentiation and polarization towards AAM phenotype We co-cultured primary human monocytes from three unique donors with a panel of five HGSOC cell lines (OV90, OVCAR4, OVCAR3, OVCA432, and OVCAR5) that have been categorized as genomically-consistent with patient samples [32]. Monocytes are non-adherent; therefore, by washing the culture prior to fixing and staining any remaining monocytes are removed. The adherent monocyte derived cells (MDCs) are expected to be either macrophages (CD68+) or dendritic cells (CD68-) [33]. In the experimental condition where monocytes were neither co-cultured with HGSOC cells nor additional serum/cytokines/growth factors very few MDCs were observed (data not shown). In contrast, published classical and alternative activation protocols resulted in robust production of $\mathrm{CD} 68+$ macrophages, with the classical activation resulting in CD163- cells and the alternative activation resulting in CD163+ for all three monocyte donors (Supplemental Figure 2). Coculture with all five lines tested resulted in MDCs; immunostaining for CD68 (Fig. 1a) confirmed that nearly all MDCs were macrophages (Fig. 1b). This is similar to prior reports where in vitro differentiation to dendritic cells by GM-CSF/IL- 4 was inhibited by soluble factors secreted by lung cancer cells [34], and suggests that monocyte differentiation in tumors is skewed towards CD68+ macrophages. While all co-cultures resulted in the production of $\mathrm{CD} 68+$ macrophages, the number varied considerably across the five HGSOC cell lines (Fig. 1c), consistent with the heterogeneity observed in

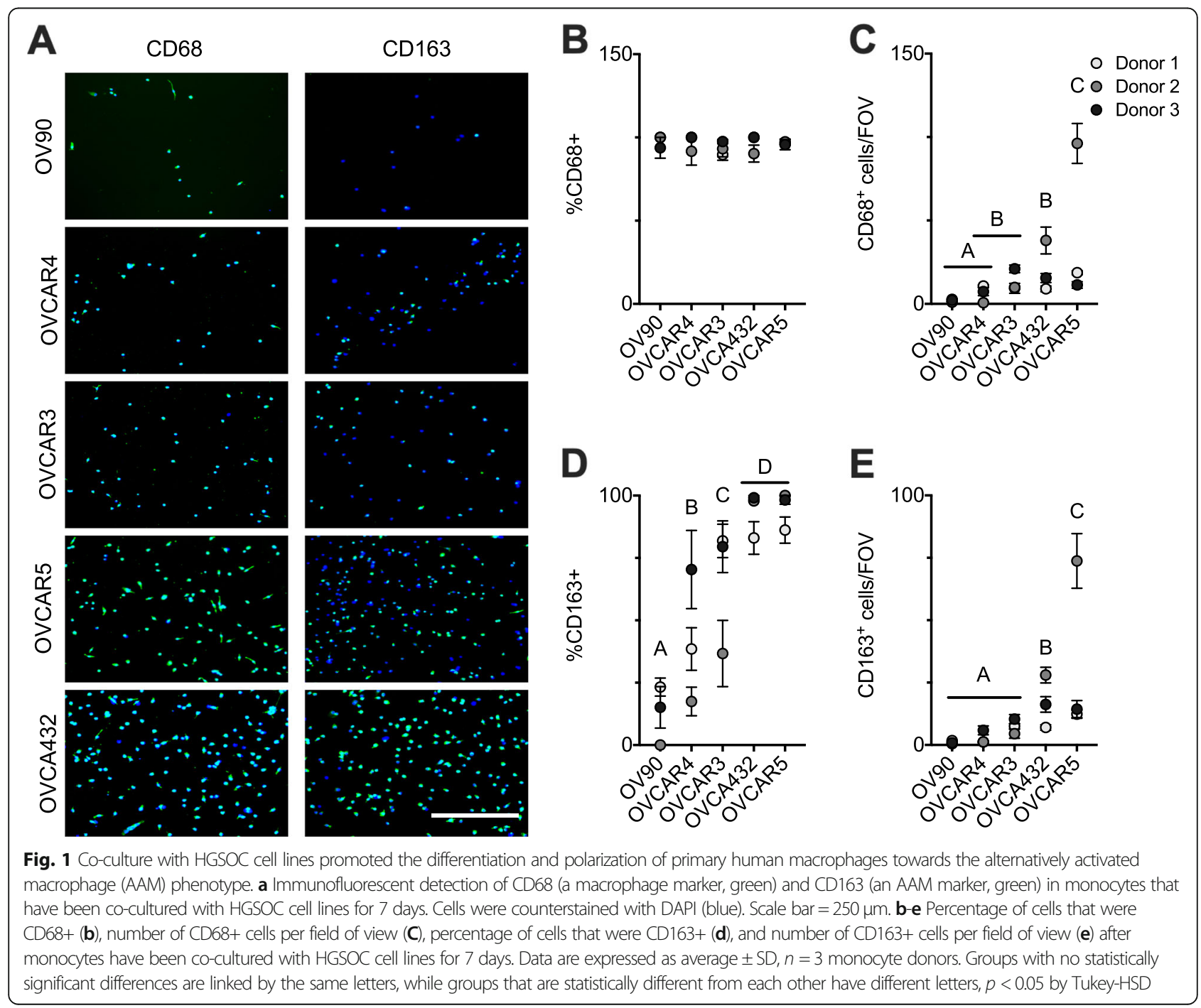


ovarian cancer $[32,35]$. When co-cultured with OV90 or OVCAR4, very few MDCs remained in the microculture device. However, when co-cultured with OVCAR3 or OVCA432, significantly more MDCs remained, and co-culture with OVCAR5 yielded the most macrophages. As the co-culture device prevents physical contact between the two cell types [20], we hypothesized that HGSOC cells were driving macrophage differentiation through soluble cues.

Given that co-culture induced macrophage differentiation, we next assessed the ability of co-culture to impact polarization to AAMs by immunostaining for CD163, an AAM specific marker (Fig. 1a). Co-culture resulted in polarization into AAMs, again with variation observed across the five HGSOC cell lines (Fig. 1d). However, here the trends were slightly different. While nearly all MDCs were CD68+ for all cell lines, the percentage of CD163+ cells differed across the tumor lines. Specifically, few of the macrophages from co-culture with OV90 polarized towards an AAM phenotype, significantly more polarized towards AAMs when cocultured with OVCAR4, even more with OVCAR3, and co-culture with OVCAR5 and OVCA432 yielded the highest percent of CD163+ cells [36]. Of course, to develop a CD163+ cell, the monocyte must first differentiate to a macrophage and then polarize; therefore, the number of CD163+ cells is a function of both the ability to differentiate and the ability to polarize. However, rather than seeing co-cultures that produced numbers of CD163+ cells that were incongruous with the number of CD68+ cells/percentage of CD163+, we observed a similar trend between CD68+ and CD163+ rankings (Fig. 1c, e). This suggests that the largest barrier to producing an AAM may be the differentiation of a monocyte to a macrophage, rather than the polarization. While macrophages can be highly plastic in terms of phenotype there is little evidence that they dedifferentiate back into monocytes [9]. Overall, while there was monocyte donor-to-donor variability, the five HGSOC cell lines consistently exhibited either a lower or higher ability to produce CD68+ macrophages from monocytes and CD163+ AAMs from macrophages. Therefore, to determine the pro-AAM potential of each cell line, we consider both the number of CD68+ cells and the number of CD163+ cells.

\section{Pro-AAM potential of HGSOC cell lines does not correlate with the secretion of established macrophage differentiation and polarization factors}

To determine which HGSOC-derived factors were responsible for the generation of macrophages/AAMs, we examined gene expression from the HGSOC cells that had been co-cultured with monocytes/MDCs using a PCR array for factors known to recruit monocytes
(CCL2), differentiate monocytes into macrophages (CSF1), polarize macrophages into AAMs (IL4, IL10, IL13), or polarize macrophages into CAMS (TNF, IFNG) (Fig. 2a). Similar expression levels were seen from HGSOC cells in monoculture or co-culture with monocytes, indicating minimal reciprocal effects from the monocytes on these pathways (Supplemental Figure 3). We did not observe an obvious correlation of gene expression of any factor with the relative CD68+/CD163+ production. MCSF, IL-4, and IL-13 are accepted as the canonical pathway that act in concert to differentiate monocytes into macrophages and subsequently polarize macrophages into AAMs [37, 38]. Intriguingly, the two cell types that produced the most CD68+/CD163+ macrophages, OVCAR5 and OVCA432, demonstrated very different gene expression patterns of the canonical CSF1, IL4, and IL3 cytokines. As our dominant effect of coculture was the production of $\mathrm{CD} 68+$ macrophages, we next directly tested the impact of blocking the canonical MCSF pathway in co-culture. While neutralizing MSCF significantly decreased the number of CD68+ cells produced from monocytes treated with exogenous MCSF, IL-4, and IL-13, it did not significantly impact the ability of CD68+ macrophages to form in co-culture with OVCAR5 and OVCA432 (Fig. 2b). Similar to the trend of differentiation being the limiting step in unperturbed co-culture, the level of CD163+ AAMs was inhibited in the canonical treatment condition plus anti-MCSF, but was unimpacted with MCSF neutralization in co-culture (Fig. 2c). This is in contrast to prior studies demonstrating that attenuation of MCSF signaling through CSF-1R inhibition in glioma led to AAM re-education towards a pro-inflammatory M1-like phenotype [39].

As it is possible that other established pathways are responsible for the observed effects of co-culture, we next examined conditioned media collected from co-cultures to test for additional soluble factors that have been reported to influence macrophage polarization or differentiation (Fig. 2d). All 14 cytokines included in the screen were detected, with variability noted across HGSOC cell lines. Similar to the gene expression data for the canonical factors, OVCAR5 and OVCA432 co-cultures had different patterns of cytokine production that did not correlate with macrophage or AAM production. We also considered whether an increase in CAM-associated cytokines could be responsible for the lower pro-AAM potential in the other three lines, as pro-inflammatory cytokines such as GM-CSF, interferon-gamma (IFN- $\gamma$ ), and IL-12 can skew macrophage populations towards the CAM phenotype and away from an AAM phenotype $[39,40]$. When we examined for univariate correlations between either gene expression levels or soluble factors and the gradient of macrophage or AAM production potential across the five HGSOC cell lines in co-culture or 


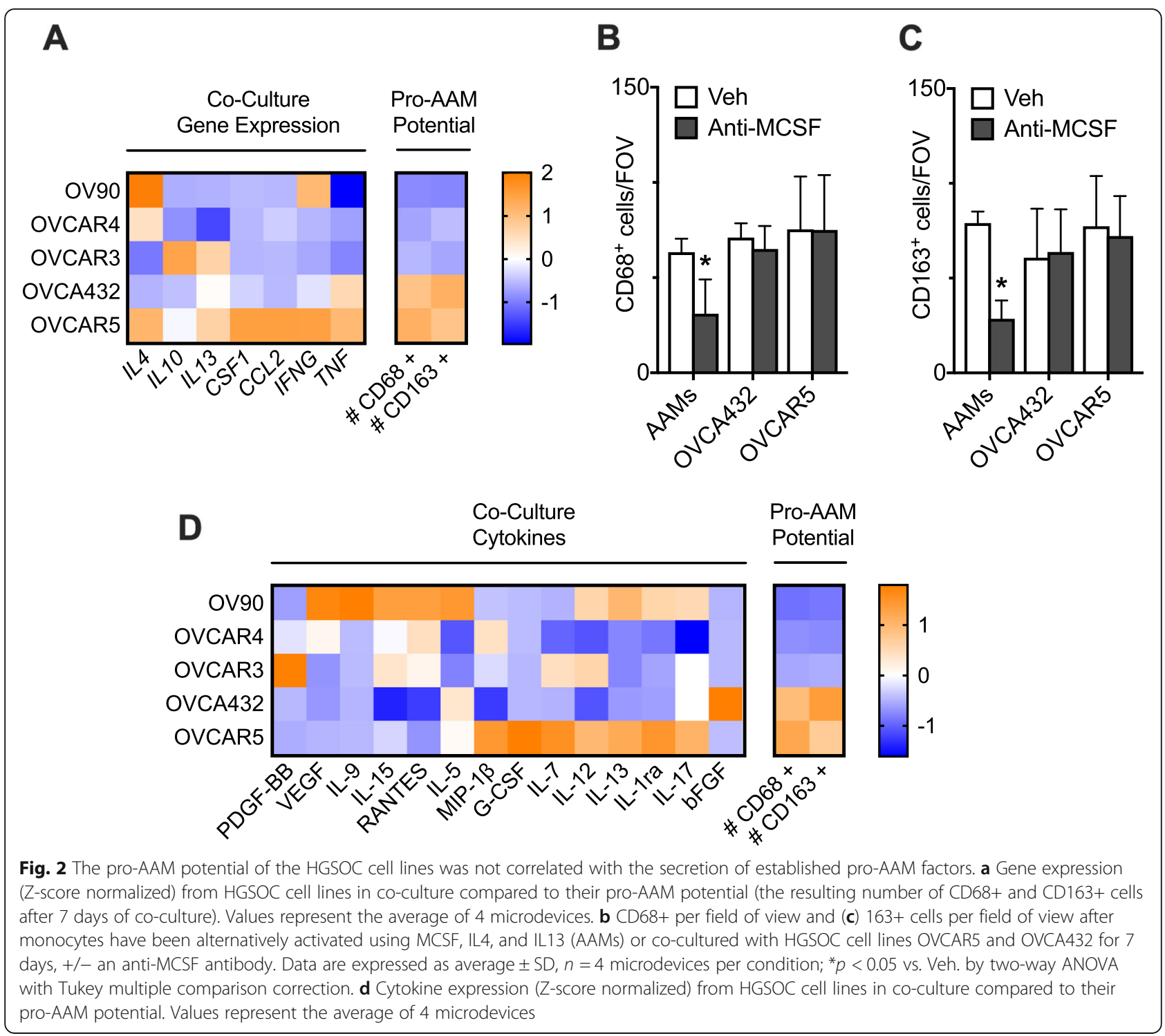

monoculture, the strongest correlation was for TNF with an $\mathrm{R}^{2}$ value of 0.73 (Supplemental Figure 3). However, this was a positive correlation and prior reports have demonstrated that TNF induces the CAM phenotype instead of the AAM phenotype [41]. Since the levels tested here reflect the production of cytokines from MDCs as well as HGSOC cells, we also tested the levels from HGSOC in monoculture (Supplemental Figure 3). While the levels of cytokines were different than in co-culture, we did not observe a correlation between any single factor and macrophage or AAM production. We also examined the potential for a multivariate relationship using partial least squares regression [42], but no such relationship was identified (data not shown). Taken together, these data suggest that HGSOC cells were not using established macrophage differentiation or AAM polarization factors and may instead utilize a noncanonical signaling mechanism.

RNA-seq analysis of HGSOC cell lines coupled with EBSeq identifies potential drivers of AAM-potential

To identify candidate factors produced by the HGSOC cells that promote macrophage differentiation and AAM polarization, we performed RNA sequencing (RNA-seq) to evaluate the global gene expression profiles of each HGSOC cell line (available here). To analyze this data, we first constructed a heatmap of pairwise Pearson's correlation coefficients of gene transcription levels (Fig. 3a), performed principal component analysis (Fig. 3b), and evaluated shared gene expression (Fig. 3c). As expected, the replicates for individual cell lines were more similar to each other than to samples from a different line. 


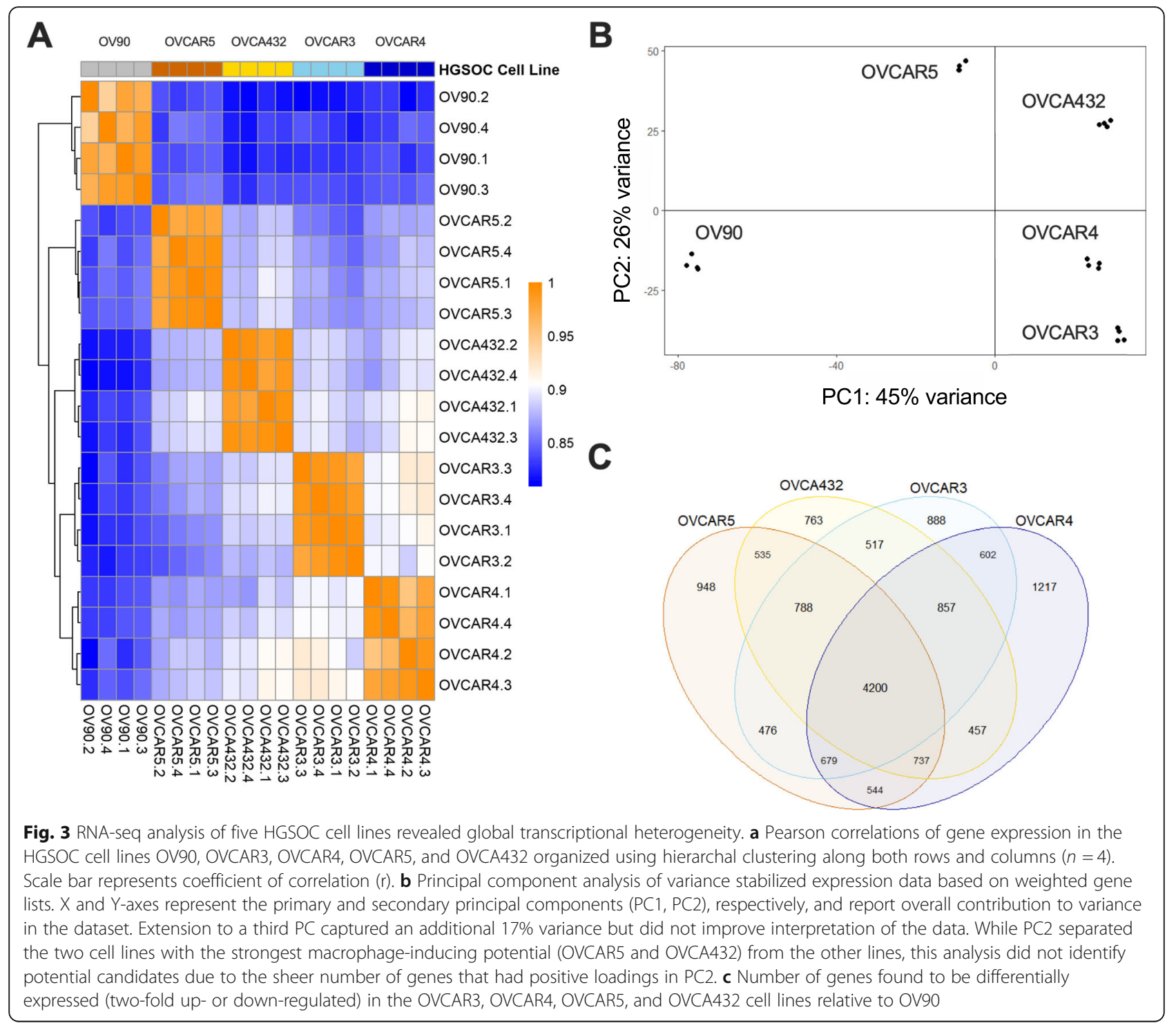

These analyses demonstrated the heterogeneity across the five HGSOC cell lines, and that OV90 was transcriptionally distinct from the other four HGSOC cell lines. However, the global differences in gene expression across the five HGSOC lines did not follow the same trend as their macrophage/AAM producing-potential and did not reveal which signaling pathways to further investigate. Therefore, we sought to evaluate patterns in the gene expression data beyond differential expression.

As a next step we employed EBSeq, an empirical Bayesian method used to identify statistically significant patterns in RNA-seq datasets [22]. EBSeq calculates the probability of a gene being either equal or unequal in a comparison. In the baseline mode, EBSeq does not examine directionality (i.e, identify gene expression patterns of greater than or lesser than between groups). To incorporate directionality, an additional logic gate was added to those that met the EBSeq criteria of belonging to a pattern of interest. Specifically, we looked for two patterns - one that matched the number of CD68+ cells (OV90 < OVCAR4 < OVCAR3 < OVCA432 < OVCAR5) and one that matched the number of CD163+ cells $(\mathrm{OV} 90<$ OVCAR4 < OVCAR3 < OVCAR5 < OVCA432. EBSeq was used to determine which genes adhered to the probability OV $90 \neq$ OVCAR 4 \&VCAR $3 \neq$ OVCAR $5 \neq$ OVCA432. This subset of genes was then further analyzed for directionality similar to the observed macrophage and AAM potential, OV90 < OVCAR4 < OVCAR3 < OVCAR5 < OVCA432. When applied to the 11,858 differentially expressed genes, EBSeq identified 277 genes as having the same expression pattern as the macrophage/AAM potential (Fig. 4a). To further narrow the list of candidates, we used curated databases to identify candidates with characteristics consistent with our observations. First, KEGG (Kyoto Encyclopedia of Genes and Genomes) Pathway Analysis [43] along with PubMed literature 


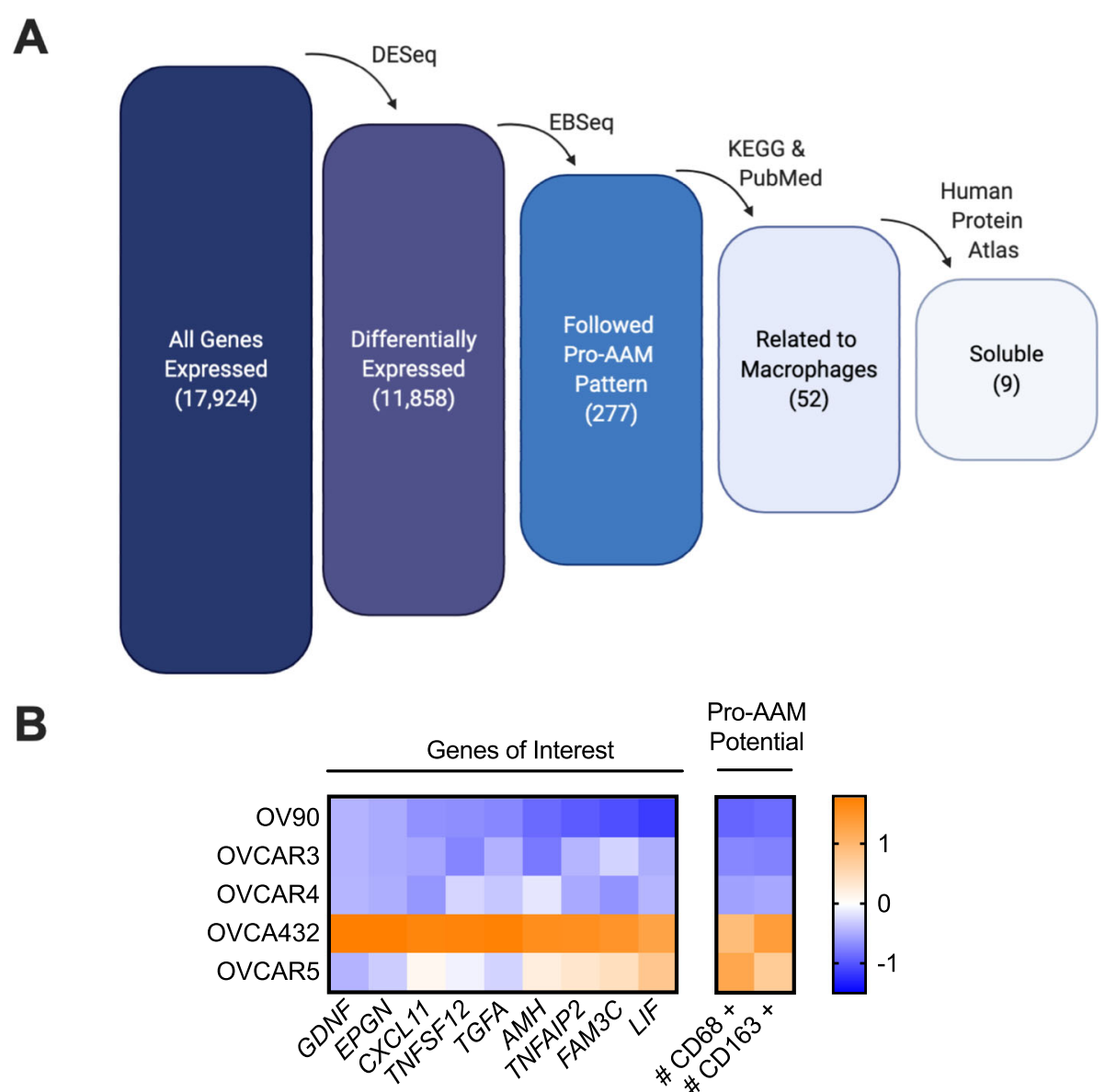

Fig. 4 RNA-seq analyzed by EBSeq identified genes whose expression mirrored the pro-AAM potential of the HGSOC cell lines. a Diagram of the process by which the nine factors of interest were identified. $\mathbf{b}$ Gene expression for the nine factors (Z-score normalized) in HGSOC cell lines compared to their pro-AAM potential; values represent the average of 4 microdevices

Table 1 Nine candidate factors identified by EBSeq analysis. Sequencing data is reported as the normalized read counts averaged among technical replicates for each cell line. References refer to previous studies supporting the role of the candidate factor in oncogenesis and/or macrophage behavior

\begin{tabular}{|c|c|c|c|c|c|c|c|}
\hline Gene Name & Gene Symbol & OV90 & OVCAR4 & OVCAR3 & OVCAR5 & OVCA432 & Ref. \\
\hline Anti-Mullerian Hormone & $A M H$ & 3.72 & 4.73 & 11.70 & 15.95 & 30.91 & {$[45,46]$} \\
\hline C-X-C Motif Chemokine Ligand 11 & CXCL11 & 0.65 & 1.06 & 0.75 & 3.36 & 9.22 & {$[47,48]$} \\
\hline Epithelial Mitogen & EPGN & 0.00 & 0.00 & 0.21 & 2.97 & 34.75 & {$[49,50]$} \\
\hline Family with Sequence Similarity 3 Member C & FAM3C & 3410.94 & 5751.98 & 4598.91 & 7852.69 & $10,933.33$ & [51] \\
\hline Glial Cell Line-Derived Neurotrophic Factor & GDNF & 0.00 & 0.00 & 0.16 & 0.00 & 47.86 & [52] \\
\hline Leukemia Inhibitory Factor & LIF & 87.28 & 586.30 & 616.71 & 1515.45 & 1895.35 & {$[28,53]$} \\
\hline Transforming Growth Factor Alpha & TGFA & 7.34 & 586.50 & 870.77 & 1035.11 & 5681.16 & {$[49,50]$} \\
\hline Tumor Necrosis Factor Alpha-Induced Protein 2 & TNFAIP2 & 2222.38 & 3571.95 & 3406.09 & 5590.16 & 8712.42 & {$[54,55]$} \\
\hline Tumor Necrosis Factor Ligand Superfamily Member 12 & TNFSF12 & 2.60 & 0.56 & 20.68 & 27.71 & 104.14 & {$[56-58]$} \\
\hline
\end{tabular}


searches were used to identify candidate genes with links to monocyte differentiation or macrophage polarization, or that are secreted by cells in tumor microenvironments or during wound healing, yielding 52 genes of interest. As the cancer cells and MDCs do not contact each other in the device, the $\mathrm{Hu}$ man Protein Atlas (https://www.proteinatlas.org/) [44] was used to identify genes that produce a soluble factor, resulting in a final list of nine genes of interest (Table 1).

\section{HGSOC-derived TGFa drives the generation of macrophages}

To interrogate select pathways identified from analysis of the RNA-seq data, co-cultures of OVCAR5 and monocytes were treated with small molecule inhibitors or blocking antibodies related to the signaling pathways exploited by the identified candidates. Specifically, family with sequence similarity 3 member C (FAM3C) signaling was inhibited using the $\gamma$-secretase inhibitor DAPT [51] and signaling downstream of leukemia inhibitory factor (LIF) and transforming growth factor alpha (TGF $\alpha$ ) was inhibited using the selective STAT3 inhibitor galiellalactone (GL) [28]. At the receptor level, signaling downstream of anti-Mullerian hormone (AMH) was inhibited using an antibody against its receptor AMHR2 [59]; and signaling downstream of TGF $\alpha$ and epigen was inhibited using an antibody against the shared receptor, EGFR [17]. Tumor necrosis factor alpha induced protein 2 (TNFAIP2) was not directly interrogated due to lack of specific inhibitors. Tumor necrosis factor superfamily member 12 (TNFSF12), C-X-C motif chemokine ligand 11 (CXCL11) and glial cell derived neurotrophic factor (GDNF) were not directly interrogated since they did
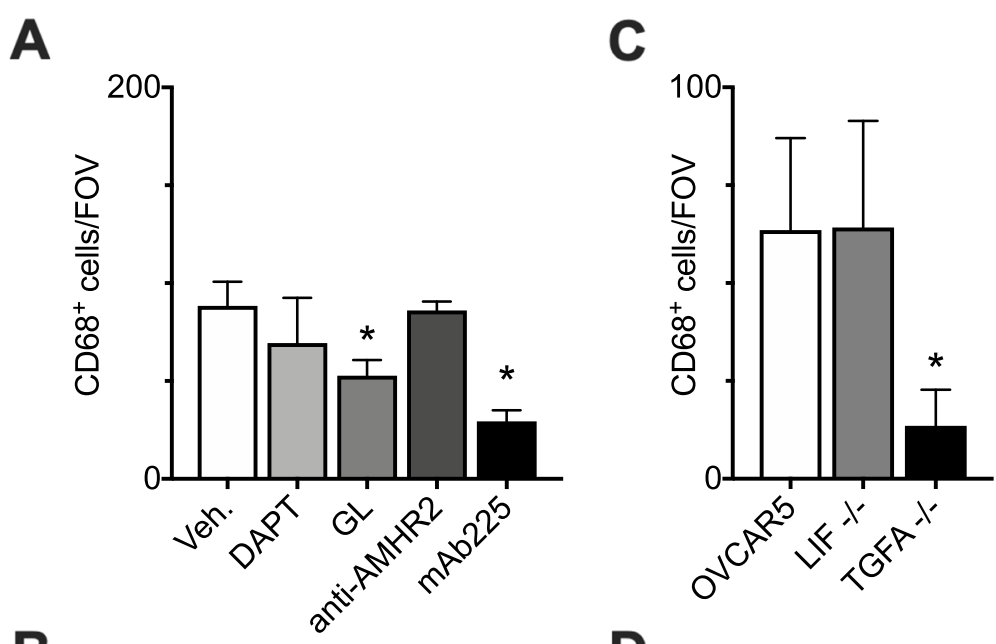

B

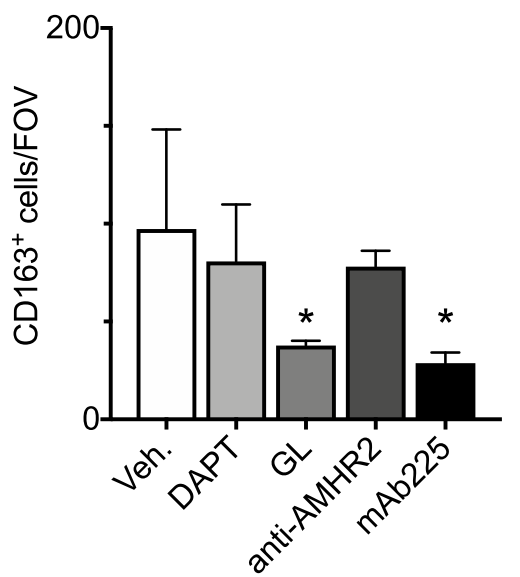

D

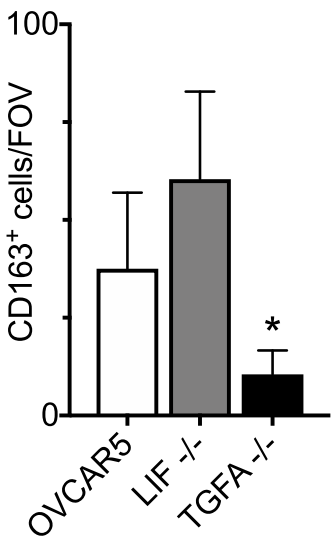

Fig. 5 HGSOC-derived TGFa drives the generation of macrophages. a, b Monocytes were co-cultured with HGSOC cell line OVCAR5 +/- vehicle control (Veh.) or inhibitors against pathways related to the genes of interest: $10 \mu \mathrm{M}$ DAPT, $5 \mu \mathrm{M} \mathrm{GL}, 20 \mathrm{ng} / \mathrm{mL}$ anti-AMH, $10 \mu \mathrm{g} / \mathrm{mL} \mathrm{mAb} 225$. a CD68+ cells per field of view and (b) CD163+ cells per field of view. Data expressed as average \pm SD, $n=3$ microdevices per condition; ${ }^{*} p<0.05$ vs. Veh. by one-way ANOVA with Dunnett multiple comparison correction. c, d Monocytes were co-cultured with HGSOC cell lines OVCAR5, OVCAR5 $5^{L F-/-}$, or OVCAR5 ${ }^{\text {TGF }-/-}$. c CD68+ cells per field of view and (d) CD163+ cells per field of view. Data expressed as average $\pm S D, n=3$ microdevices per condition; ${ }^{*} p<0.05$ vs. OVCAR5 by one-way ANOVA with Tukey multiple comparison correction 
not match the pro-AAM pattern as strongly as the other candidates.

Of the five inhibitors tested, GL and mAb225 significantly reduced the number of CD68+ cells (Fig. 5a) as well as number of CD163+ cells (Fig. 5b) after 7 days of coculture, suggesting a role for LIF (GL inhibition), TGF $\alpha$ (GL and mAb225 inhibition), or epigen (mAb225). However, since the inhibitors were added to co-culture we could not discern if they were inhibiting HGSOC or MDC derived epigen, TGF $\alpha$ or LIF. Therefore, we next used CRISPR to produce ovarian cancer lines with the specific factor knocked down in OVCAR5. CRISPR attempts in OVCA432 were unsuccessful due to the cell line not tolerating the low densities needed for the protocol (data not shown). Examination of the expression levels in OVCAR5 demonstrated that TGFA had significantly higher expression levels compared to EPGN (Supplemental Figure 4); therefore we only generated OVCAR $5^{\text {TGFA- }}$ and OVCAR $5^{\text {LIF-/- }}$. TIDE analysis yielded 84.1 and $87.8 \%$ of OVCAR5 cells containing an insertion or deletion mutation at the target site in the TGFA or LIF loci, with $\mathrm{R}^{2}=$ 0.87 and $R^{2}=0.91$ respectively (Supplemental Figure 4). At the protein level, the respective CRISPR lines had either non-detectable TGF $\alpha$ or significantly reduced LIF production (Supplemental Figure 4).

Monocytes were then co-cultured with OVCAR5, OVCAR $5^{\text {TGFA-/- }}$, or OVCAR5 $5^{\text {LIF-/- }}$ and the resulting number of CD68+ and CD163+ MDCs were evaluated. Culturing monocytes with OVCAR $5^{\text {LIF-/- }}$ did not reduce the total number of CD68+ or CD163+ cells per field of view compared to monocytes co-cultured with OVCAR5 (Fig. 5c, d). While LIF is elevated in ascites fluid in ovarian cancer and can promote the generation of AAMs, it does so in an IL-6 and MCSF-dependent manner [53]. Therefore, the fact that we did not see an effect from knocking out LIF may be because the observed macrophage/AAM potential in our system was independent of MCSF. In contrast, culturing monocytes with OVCAR5 $5^{\text {TGFA-/- }}$ significantly reduced the total number of both $\mathrm{CD} 68+$ and CD163+ cells to approximately $25 \%$ of the amount from co-culture with OVCAR5. Similar to our results in baseline co-cultures (Fig. 1), the total number of CD163+ cells closely matched those of the total number of CD68+ cells with either OVCAR5 ${ }^{L I F-/-}$ or OVCAR5 $5^{\text {TGFA-/- }}$, supporting the notion that monocyte to macrophage differentiation is the limiting step in AAM production, rather than AAM polarization. Taken together, these data indicate that TGF $\alpha$ produced by HGSOC cells supports monocyte differentiation into macrophages via EGFR.

\section{Discussion}

TGF $\alpha$ has been previously linked to ovarian cancer progression. For example, TGF $\alpha$ levels have been shown to be elevated in the ascites fluid of patients with stage III/
IV ovarian cancer compared to stage I/II [60]. Additionally, histological examinations of the epithelial portion of ovarian tumors [61] and characterization of ovarian cancer lines [62] have shown that some ovarian cancer cells produce TGF $\alpha$, consistent with our findings here. TGF $\alpha$ has also been shown to be involved in tumor cell/stromal cell interactions in ovarian cancer. For example, in a mouse model of ovarian cancer, tumor cell-derived TNF $\alpha$ induced omental fibroblasts to produce TGF $\alpha$, which in turn stimulated ovarian cancer EGFR and accelerated metastatic potential [63]. Here we demonstrate that loss of HGSOC-derived TGF $\alpha$ resulted in a significant decrease in the total number of macrophages or AAMs produced in co-culture. These data suggest that TGF $\alpha$ promotes monocyte to macrophage differentiation rather than macrophage to AAM polarization. While the immunomodulatory role of TGF $\alpha$ has not been previously investigated in ovarian cancer, increased TGF $\alpha$ expression has been correlated with increased levels of macrophages in breast cancer. In a recent histological analysis of patients with breast cancer bone metastases, tissue surrounding the tumors exhibited increased macrophage coverage as well as increased TGF $\alpha$ expression compared to the tumor tissue [64]. Additionally, knockdown of TGFA in a human breast cancer cell line used in a mouse model of breast cancer decreased the total number of macrophages present in the tumors as well as tumor growth [65]. In vitro, knocking down TGFA did not reduce breast cancer cell production of MCSF, but did reduce the expression of CCL2, leading the authors to conclude that breast cancer cell-derived TGF $\alpha$ induced autocrine EGFR signaling, leading to increased CCL2 and macrophage recruitment [65]. In contrast, our findings suggest that cancer cell-derived TGF $\alpha$ can directly support macrophage differentiation.

Epidemiological data support that patients with elevated numbers of tumor associated macrophages have a worse outcome for ovarian cancer as well as other types of cancer [66-68]. Key points where tumor cells have the ability to influence the number of macrophages in solid tumors include the recruitment of circulating monocytes and the differentiation of monocytes to macrophages. Ovarian cancer cells have been shown to express the canonical monocyte recruitment factors, CCL2 and CCL7 [69, 70]. In vivo, production of CCL2 by metastatic breast cancer cells has been shown to increase recruitment of inflammatory monocytes [71]. In a similar manner, differentiation can result from tumor cell expression and secretion of the canonical factor, MCSF [38]. Interestingly, our results demonstrated that production of $\mathrm{CD} 68+$ macrophages by ovarian cancer cells was independent of MCSF. Recent studies have demonstrated that other mechanisms can support macrophage production, such as secretion of retinoic 
acid by sarcoma cells that blocks differentiation of monocytes to dendritic cells [72]. To our knowledge, a direct role for TGF $\alpha$ in this process has not been reported.

In addition to influencing macrophage differentiation, prior studies have demonstrated that ovarian cancer cells can direct macrophage polarization to the alternative phenotype [47]. One possible mechanism for this is tumor cell production of hyaluronic acid, which leads to increased cholesterol efflux in macrophages; the resulting alteration in macrophage lipid rafts led to increased gene expression in response to exogenous IL-4 and suppressed gene expression in response to IFN $\gamma$ [73]. A key difference between our work and these studies is that most prior studies of macrophage polarization use monocyte-derived macrophages produced by canonical differentiation with MCSF, rather than tumor celldirected differentiation [74]. In the paradigm of full differentiation and polarization by tumor cells alone, our results do not support a clear role for TGF $\alpha$ in polarization, as the primary effect of inhibiting TGF $\alpha$ is the loss of CD68+ macrophages rather than a shift in the percentage of CD163+ macrophages.

\section{Conclusions}

Our findings add TGF $\alpha$ as a novel factor that tumor cells can use to directly promote macrophage differentiation. This finding was enabled by a combination of a controlled in vitro co-culture model, bioinformatic analysis of gene expression and phenotype patterns, and rigorous tests of candidate factors identified in our screen. Combined with other studies demonstrating effects of tumor cells on monocyte recruitment, macrophage polarization, and macrophage influence on tumor cells [16-18], it is evident that tumor cell-macrophage interactions are complex and multi-faceted, providing multiple opportunities for intervention to slow tumor progression.

\section{Supplementary information}

Supplementary information accompanies this paper at https://doi.org/10 1186/s12885-020-07513-w.

Additional file 1: Supplemental Figure 1. Ability of the five HGSOC cell lines to produce CD68+ and CD163+ cells compared to the resulting two conditions of interest for EBSeq. (A) CD68+ per field of view and (B) CD163+ cells per field of view after monocytes have been co-cultured with HGSOC cell lines for seven days. Data are expressed as average \pm SD, $n=3$ monocyte donors. Groups with no statistically significant differences are linked by the same letters, while groups that are statistically different from each other have different letters, $p<0.05$ by Tukey-HSD. (D, E) Conditions of interest for EBSeq that mimic either the number of $\mathrm{CD} 68+$ or CD163+ cells after co-culture with HGSOC: $\mathrm{C1}: \mu 1=\mu 2=\mu 3<\mu 4<\mu 5$; $C 2: \mu 1=\mu 2=\mu 3<\mu 4>\mu 5$

Additional file 2: Supplemental Figure 2. Immunofluorescent detection of CD68 (a macrophage marker, green) and CD163 (an AAM marker, green) in CAM and AAM controls after seven days of culture. Cells were counter stained with DAPI (blue). Scale bar $=250 \mu \mathrm{m}$.

Additional file 3: Supplemental Figure 3. (A) Gene expression (Zscore normalized) from HGSOC cell lines in monoculture compared to their pro-AAM potential (the resulting number of CD68+ and CD163+ cells after monocytes have been co-cultured with $\mathrm{HGSOC}$ cell lines OV90, OVCAR4, OVCAR4, OVCAR5, or OVCA432 for seven days); values represent the average of 4 microdevices. (B) Correlation between TNF fold change in co-culture relative to OV90 TNF expression in co-culture and \#CD163+ cells/FOV. (C) Cytokine expression (Z-score normalized) from HGSOC cell lines in monoculture compared to their pro-AAM potential; values represent the average of 4 microdevices.

Additional file 4: Supplemental Figure 4. (A,B) Normalized read counts of (A) EPGN and (B) TGFA from RNA-seq analysis of five HGSOC cell lines. Note the difference of scales between EPGN and TGFA. (C) TIDE analysis yielded $87.8 \%$ of OVCAR5 cells containing an insertion or deletion mutation at the target site in the LIF loci, with $R^{2}=0.91$. (D) Conditioned media was collected from OVCAR5 and OVCAR5 $5^{L / F}-1$ after $24 \mathrm{~h}$ and analyzed for LIF. Data are expressed as average \pm SD, $n=4$ microdevices per condition; ${ }^{*} p<0.05$ vs. by t-test. (E) TIDE analysis yielded $84.1 \%$ of OVCAR5 cells containing an insertion or deletion mutation at the target site in the TGFA loci, with $R^{2}=0.87$. $(\mathbf{F})$ Conditioned media was collected from OVCAR5 and OVCAR5 ${ }^{\text {TGFA }-/-}$ after $24 \mathrm{~h}$ and analyzed for TGFa. Data are expressed as average $\pm \mathrm{SD}, n=4$ microdevices per condition; ${ }^{*} p<$ 0.05 by t-test.

\section{Abbreviations}

HGSOC: High grade serous ovarian carcinoma; AAM: Alternatively activated macrophage; CAM: Classically activated macrophage; PDMS: Polydimethyl siloxane; PBS: Phosphate buffered saline; MDC: Monocyte derived cell

\section{Acknowledgements}

We thank the University of Wisconsin Microtechnology Core supported by $\mathrm{NIH}$ 5P30CA014520 for providing BioPlex support and the University of Wisconsin Bioinformatics Resource Center for providing RNA-seq support.

\section{Authors' contributions}

KCF: Conceptualization, Methodology, Validation, Formal Analysis, Investigation, Writing - Original Draft, Visualization, Project Administration, Funding Acquisition. AEM: Formal Analysis, Investigation, Visualization, Writing - Review \& Editing. YL: Data curation, Formal Analysis, Investigation. WF: Formal Analysis, Investigation. AW: Formal Analysis, Investigation. AO: Formal Analysis, Investigation. CK: Software, Resources, Supervision, Funding Acquisition, Writing - Review \& Editing. PKK: Conceptualization, Resources, Supervision, Funding Acquisition, Writing - Review \& Editing. All authors have read and approved the manuscript.

\section{Funding}

Funding was provided by the American Cancer Society (RSG-13-026-01-CSM and Midwest Division supplement to P.K. Kreeger), NIH (1DP2CA195766, 1R01CA232517, R21CA227922 to P.K. Kreeger, (NIH GM102756 to C. Kendziorski), and the Marsha Rivkin Center for Ovarian Cancer Research (Scientific Scholar Fellowship Award Number 567593) to K.C. Fogg. The funders had no role in study design, decision to publish, or preparation of the manuscript.

\section{Availability of data and materials}

The RNA-seq dataset generated during this study has been deposited on the NCBI sequence read archive (SRA; SUB7817574). The additional data generated during this study are available from the corresponding author on reasonable request.

\section{Ethics approval and consent to participate}

This study was reviewed by the University of Wisconsin IRB and declared to be not humans subject research as blood was acquired from a third party and provided as deidentified material. 


\section{Competing interests}

The authors declare that they have no competing interests.

\section{Author details}

${ }^{1}$ Department of Biomedical Engineering, University of Wisconsin-Madison, 1111 Highland Ave, WIMR 4553, Madison, WI 53705, USA. ²Department of Biostatistics and Medical Informatics, University of Wisconsin School of Medicine and Public Health, Madison, WI, USA. ${ }^{3}$ Department of Obstetrics and Gynecology, University of Wisconsin School of Medicine and Public Health, Madison, WI, USA. ${ }^{4}$ Department of Cell and Regenerative Biology, University of Wisconsin School of Medicine and Public Health, Madison, WI, USA. ${ }^{5}$ University of Wisconsin Carbone Cancer Center, University of Wisconsin School of Medicine and Public Health, Madison, WI, USA

\section{Received: 25 July 2020 Accepted: 8 October 2020}

Published online: 17 October 2020

\section{References}

1. Bowtell DD, Böhm S, Ahmed AA, Aspuria PJ, Bast RC, Beral V, et al. Rethinking ovarian cancer II: reducing mortality from high-grade serous ovarian cancer. Nat Rev Cancer. 2015;15(11):668-79.

2. Siegel RL, Miller KD, Jemal A. Cancer statistics, 2016. CA Cancer J Clin. 2016; 66(1):7-30.

3. Luo Z, Wang Q, Lau WB, Lau B, Xu L, Zhao L, et al. Tumor microenvironment: the culprit for ovarian cancer metastasis? Cancer Lett. 2016;377(2):174-82.

4. Worzfeld T, Pogge von Strandmann E, Huber M, Adhikary T, Wagner U, Reinartz S, et al. The Unique molecular and cellular microenvironment of ovarian cancer. Front Oncol. 2017;7:24.

5. Bingle L, Brown NJ, Lewis CE. The role of tumour-associated macrophages in tumour progression: implications for new anticancer therapies. J Pathol. 2002;196(3):254-65.

6. Martinez FO, Sica A, Mantovani A, Locati M. Macrophage activation and polarization. Front Biosci. 2008;13:453-61.

7. Ballotta V, Driessen-Mol A, Bouten CV, Baaijens FP. Strain-dependent modulation of macrophage polarization within scaffolds. Biomaterials. 2014; 35(18):4919-28.

8. Chen X, Ying X, Wang X, Wu X, Zhu Q. Exosomes derived from hypoxic epithelial ovarian cancer deliver microRNA-940 to induce macrophage M2 polarization. Oncol Rep. 2017;38(1):522-8.

9. Shapouri-Moghaddam A, Mohammadian S, Vazini H, Taghadosi M, Esmaeili SA, Mardani F, et al. Macrophage plasticity, polarization, and function in health and disease. J Cell Physiol. 2018;233(9):6425-40.

10. Poh AR, Ernst M. Targeting macrophages in Cancer: from bench to bedside. Front Oncol. 2018;8:49.

11. Ramanathan $\mathrm{S}$, Jagannathan N. Tumor associated macrophage: a review on the phenotypes, traits and functions. Iran J Cancer Prev. 2014;7(1):1-8.

12. Lan C, Huang $X$, Lin $S$, Huang $H$, Cai Q, Wan T, et al. Expression of M2polarized macrophages is associated with poor prognosis for advanced epithelial ovarian cancer. Technol Cancer Res Treat. 2013;12(3):259-67.

13. Reinartz S, Schumann T, Finkernagel F, Wortmann A, Jansen JM, Meissner W, et al. Mixed-polarization phenotype of ascites-associated macrophages in human ovarian carcinoma: correlation of CD163 expression, cytokine levels and early relapse. Int J Cancer. 2014;134(1):32-42.

14. Maccio A, Gramignano G, Cherchi MC, Tanca L, Melis L, Madeddu C. Role of M1-polarized tumor-associated macrophages in the prognosis of advanced ovarian cancer patients. Sci Rep. 2020;10(1):6096.

15. Etzerodt A, Moulin M, Doktor TK, Delfini M, Mossadegh-Keller N, Bajenoff M, et al. Tissue-resident macrophages in omentum promote metastatic spread of ovarian cancer. J Exp Med. 2020;217(4):e20191869.

16. Carroll MJ, Fogg KC, Patel HA, Krause HB, Mancha AS, Patankar MS, et al. Alternatively-activated macrophages Upregulate Mesothelial expression of P-Selectin to enhance adhesion of ovarian Cancer cells. Cancer Res. 2018; 78(13):3560-73.

17. Carroll MJ, Kapur A, Felder M, Patankar MS, Kreeger PK. M2 macrophages induce ovarian cancer cell proliferation via a heparin binding epidermal growth factor/matrix metalloproteinase 9 intercellular feedback loop. Oncotarget. 2016;7(52):86608-20.

18. Fogg KC, Olson WR, Miller JN, Khan A, Renner C, Hale I, et al. Alternatively activated macrophage-derived secretome stimulates ovarian cancer spheroid spreading through a JAK2/STAT3 pathway. Cancer Lett. 2019;458: 92-101.

19. Weisser SB, McLarren KW, Kuroda E, Sly LM. Generation and characterization of murine alternatively activated macrophages. Methods Mol Biol. 2013;946: 225-39.

20. Carroll MJ, Stopfer LE, Kreeger PK. A simplified culture system to examine soluble factor interactions between mammalian cells. Chem Commun (Camb). 2014;50(40):5279-81.

21. Tjiu JW, Chen JS, Shun CT, Lin SJ, Liao YH, Chu CY, et al. Tumor-associated macrophage-induced invasion and angiogenesis of human basal cell carcinoma cells by cyclooxygenase-2 induction. J Invest Dermatol. 2009; 129(4):1016-25.

22. Leng N, Dawson JA, Thomson JA, Ruotti V, Rissman Al, Smits BM, et al. EBSeq: an empirical Bayes hierarchical model for inference in RNA-seq experiments. Bioinformatics. 2013;29(8):1035-43.

23. Gentleman RC, Carey VJ, Bates DM, Bolstad B, Dettling M, Dudoit S, et al. Bioconductor: open software development for computational biology and bioinformatics. Genome Biol. 2004;5(10):R80.

24. Love Ml, Huber W, Anders S. Moderated estimation of fold change and dispersion for RNA-seq data with DESeq2. Genome Biol. 2014;15(12):550.

25. Kolde R. pheatmap: Pretty Heatmaps. R package version 1.0.12. ed. 2019.

26. Ritchie ME, Phipson B, Wu D, Hu Y, Law CW, Shi W, et al. Limma powers differential expression analyses for RNA-sequencing and microarray studies. Nucleic Acids Res. 2015;43(7):e47.

27. Kerr G, Sheldon H, Chaikuad A, Alfano I, von Delft F, Bullock AN, et al. A small molecule targeting ALK1 prevents notch cooperativity and inhibits functional angiogenesis. Angiogenesis. 2015;18(2):209-17.

28. Rebe C, Vegran F, Berger H, Ghiringhelli F. STAT3 activation: a key factor in tumor immunoescape. JAKSTAT. 2013;2(1):e23010.

29. Labun K, Montague TG, Krause M, Torres Cleuren YN, Tjeldnes H, Valen E. CHOPCHOP v3: expanding the CRISPR web toolbox beyond genome editing. Nucleic Acids Res. 2019:47(W1):W171-W4.

30. Sanjana NE, Shalem O, Zhang F. Improved vectors and genome-wide libraries for CRISPR screening. Nat Methods. 2014;11(8):783-4.

31. Brinkman EK, Chen T, Amendola M, van Steensel B. Easy quantitative assessment of genome editing by sequence trace decomposition. Nucleic Acids Res. 2014;42(22):e168.

32. Domcke S, Sinha R, Levine DA, Sander C, Schultz N. Evaluating cell lines as tumour models by comparison of genomic profiles. Nat Commun. 2013;4: 2126.

33. Betjes MG, Haks MC, Tuk CW, Beelen RH. Monoclonal antibody EBM11 (antiCD68) discriminates between dendritic cells and macrophages after shortterm culture. Immunobiology. 1991;183(1-2):79-87.

34. Avila-Moreno F, Lopez-Gonzalez JS, Galindo-Rodriguez G, Prado-Garcia H, Bajana S, Sanchez-Torres C. Lung squamous cell carcinoma and adenocarcinoma cell lines use different mediators to induce comparable phenotypic and functional changes in human monocyte-derived dendritic cells. Cancer Immunol Immunother. 2006;55(5):598-611.

35. Bourgeois DL, Kabarowski KA, Porubsky VL, Kreeger PK. High-grade serous ovarian cancer cell lines exhibit heterogeneous responses to growth factor stimulation. Cancer Cell Int. 2015;15:112.

36. Fortis SP, Sofopoulos M, Sotiriadou NN, Haritos C, Vaxevanis CK, Anastasopoulou EA, et al. Differential intratumoral distributions of CD8 and CD163 immune cells as prognostic biomarkers in breast cancer. J Immunother Cancer. 2017;5:39.

37. Ruffell B, Affara NI, Coussens LM. Differential macrophage programming in the tumor microenvironment. Trends Immunol. 2012;33(3):119-26.

38. Van Overmeire E, Stijlemans B, Heymann F, Keirsse J, Morias Y, Elkrim Y, et al. M-CSF and GM-CSF receptor signaling differentially regulate monocyte maturation and macrophage polarization in the tumor microenvironment Cancer Res. 2016;76(1):35-42.

39. Pyonteck SM, Akkari L, Schuhmacher AJ, Bowman RL, Sevenich L, Quail DF, et al. CSF-1R inhibition alters macrophage polarization and blocks glioma progression. Nat Med. 2013;19(10):1264-72.

40. Josephs DH, Bax HJ, Karagiannis SN. Tumour-associated macrophage polarisation and re-education with immunotherapy. Front Biosci (Elite Ed). 2015;7:293-308.

41. Parameswaran N, Patial S. Tumor necrosis factor-alpha signaling in macrophages. Crit Rev Eukaryot Gene Expr. 2010;20(2):87-103.

42. Kreeger PK. Using partial least squares regression to analyze cellular response data. Sci Signal. 2013;6(271):tr7. 
43. Kanehisa M, Furumichi M, Tanabe M, Sato Y, Morishima K. KEGG: new perspectives on genomes, pathways, diseases and drugs. Nucleic Acids Res. 2017:45(D1):D353-D61.

44. Thul PJ, Akesson L, Wiking M, Mahdessian D, Geladaki A, Ait Blal H, et al. A subcellular map of the human proteome. Science. 2017;356(6340):eaal3321.

45. Beck TN, Korobeynikov VA, Kudinov AE, Georgopoulos R, Solanki NR, Andrews-Hoke $M$, et al. Anti-Müllerian hormone signaling regulates epithelial plasticity and Chemoresistance in lung Cancer. Cell Rep. 2016; 16(3):657-71.

46. Bougherara $H$, Némati F, Nicolas A, Massonnet $G$, Pugnière M, Ngô C, et al. The humanized anti-human AMHRII mAb 3C23K exerts an anti-tumor activity against human ovarian cancer through tumor-associated macrophages. Oncotarget. 2017;8(59):99950-65.

47. Hagemann T, Wilson J, Burke F, Kulbe H, Li NF, Pluddemann A, et al. Ovarian cancer cells polarize macrophages toward a tumor-associated phenotype. J Immunol. 2006;176(8):5023-32.

48. Torraca V, Cui C, Boland R, Bebelman JP, van der Sar AM, Smit MJ, et al. The CXCR3-CXCL11 signaling axis mediates macrophage recruitment and dissemination of mycobacterial infection. Dis Model Mech. 2015;8(3):253-69.

49. Zhao G, Liu L, Peek RM, Hao X, Polk DB, Li H, et al. Activation of epidermal growth factor receptor in macrophages mediates feedback inhibition of $\mathrm{M} 2$ polarization and gastrointestinal tumor cell growth. J Biol Chem. 2016; 291(39):20462-72.

50. Lamb DJ, Modjtahedi H, Plant NJ, Ferns GA. EGF mediates monocyte chemotaxis and macrophage proliferation and EGF receptor is expressed in atherosclerotic plaques. Atherosclerosis. 2004;176(1):21-6.

51. Lahsnig C, Mikula M, Petz M, Zulehner G, Schneller D, van Zijl F, et al. ILEl requires oncogenic Ras for the epithelial to mesenchymal transition of hepatocytes and liver carcinoma progression. Oncogene. 2009;28(5):638-50.

52. Rusmini M, Griseri P, Matera I, Pontarini E, Ravazzolo R, Mavilio D, et al. Expression variability and function of the RET gene in adult peripheral blood mononuclear cells. J Cell Physiol. 2014;229(12):2027-37.

53. Duluc D, Delneste Y, Tan F, Moles MP, Grimaud L, Lenoir J, et al. Tumorassociated leukemia inhibitory factor and IL-6 skew monocyte differentiation into tumor-associated macrophage-like cells. Blood. 2007; 110(13):4319-30.

54. Thair SA, Topchiy E, Boyd JH, Cirstea M, Wang C, Nakada TA, et al. TNFAIP2 inhibits early TNFa-induced NF-x03BA;B signaling and decreases survival in septic shock patients. J Innate Immun. 2016;8(1):57-66.

55. Jia L, Shi Y, Wen Y, Li W, Feng J, Chen C. The roles of TNFAIP2 in cancers and infectious diseases. J Cell Mol Med. 2018;22(11):5188-95.

56. Xia Y, Campbell SR, Broder A, Herlitz L, Abadi M, Wu P, et al. Inhibition of the TWEAK/Fn14 pathway attenuates renal disease in nephrotoxic serum nephritis. Clin Immunol. 2012;145(2):108-21.

57. Kim SH, Kang YJ, Kim WJ, Woo DK, Lee Y, Kim DI, et al. TWEAK can induce pro-inflammatory cytokines and matrix metalloproteinase-9 in macrophages. Circ J. 2004;68(4):396-9.

58. Roos A, Dhruv HD, Mathews IT, Inge $\sqcup$, Tuncali S, Hartman LK, et al. Identification of aurintricarboxylic acid as a selective inhibitor of the TWEAKFn14 signaling pathway in glioblastoma cells. Oncotarget. 2017;8(7):12234-46.

59. Guven S, Lindsey JS, Poudel I, Chinthala S, Nickerson MD, Gerami-Naini B, et al. Functional maintenance of differentiated embryoid bodies in microfluidic systems: a platform for personalized medicine. Stem Cells Transl Med. 2015:4(3):261-8.

60. Saltzman AK, Hartenbach EM, Carter JR, Contreras DN, Twiggs LB, Carson LF, et al. Transforming growth factor-alpha levels in the serum and ascites of patients with advanced epithelial ovarian cancer. Gynecol Obstet Investig. 1999:47(3):200-4.

61. Doraiswamy V, Parrott JA, Skinner MK. Expression and action of transforming growth factor alpha in normal ovarian surface epithelium and ovarian cancer. Biol Reprod. 2000;63(3):789-96.

62. Prasasya RD, Vang KZ, Kreeger PK. A multivariate model of ErbB network composition predicts ovarian cancer cell response to canertinib. Biotechnol Bioeng. 2012;109(1):213-24

63. Lau TS, Chan LK, Wong EC, Hui CW, Sneddon K, Cheung TH, et al. A loop of cancer-stroma-cancer interaction promotes peritoneal metastasis of ovarian cancer via TNFalpha-TGFalpha-EGFR. Oncogene. 2017;36(25):3576-87.

64. Sun J, Cui H, Gao Y, Pan Y, Zhou K, Huang J, et al. TGF-alpha overexpression in breast Cancer bone metastasis and primary lesions and TGF-alpha enhancement of expression of Procancer metastasis cytokines in bone marrow Mesenchymal stem cells. Biomed Res Int. 2018;2018:6565393.
65. Nickerson NK, Mill CP, Wu HJ, Riese DJ 2nd, Foley J. Autocrine-derived epidermal growth factor receptor ligands contribute to recruitment of tumor-associated macrophage and growth of basal breast cancer cells in vivo. Oncol Res. 2013;20(7):303-17.

66. Zhang M, He Y, Sun X, Li Q, Wang W, Zhao A, et al. A high M1/M2 ratio of tumor-associated macrophages is associated with extended survival in ovarian cancer patients. J Ovarian Res. 2014;7:19.

67. Zhang Y, Cheng S, Zhang M, Zhen L, Pang D, Zhang Q, et al. Highinfiltration of tumor-associated macrophages predicts unfavorable clinical outcome for node-negative breast cancer. PLoS One. 2013;8(9):e76147.

68. Ding T, Xu J, Wang F, Shi M, Zhang Y, Li SP, et al. High tumor-infiltrating macrophage density predicts poor prognosis in patients with primary hepatocellular carcinoma after resection. Hum Pathol. 2009;40(3):381-9.

69. Fader AN, Rasool N, Vaziri SA, Kozuki T, Faber PW, Elson P, et al. CCL2 expression in primary ovarian carcinoma is correlated with chemotherapy response and survival outcomes. Anticancer Res. 2010;30(12):4791-8.

70. Zsiros E, Duttagupta P, Dangaj D, Li H, Frank R, Garrabrant T, et al. The ovarian Cancer chemokine landscape is conducive to homing of vaccineprimed and CD3/CD28-Costimulated T cells prepared for adoptive therapy. Clin Cancer Res. 2015;21(12):2840-50.

71. Qian BZ, Li J, Zhang H, Kitamura T, Zhang J, Campion LR, et al. CCL2 recruits inflammatory monocytes to facilitate breast-tumour metastasis. Nature. 2011;475(7355):222-5.

72. Devalaraja S, To TKJ, Folkert IW, Natesan R, Alam MZ, Li M, et al. Tumorderived retinoic acid regulates Intratumoral monocyte differentiation to promote immune suppression. Cell. 2020;180(6):1098-114 e16.

73. Goossens P, Rodriguez-Vita J, Etzerodt A, Masse M, Rastoin O, Gouirand V, et al. Membrane cholesterol efflux drives tumor-associated macrophage reprogramming and tumor progression. Cell Metab. 2019;29(6):1376-89 e4.

74. Park KY, Li G, Platt MO. Monocyte-derived macrophage assisted breast cancer cell invasion as a personalized, predictive metric to score metastatic risk. Sci Rep. 2015;5:13855.

\section{Publisher's Note}

Springer Nature remains neutral with regard to jurisdictional claims in published maps and institutional affiliations.

Ready to submit your research? Choose BMC and benefit from:

- fast, convenient online submission

- thorough peer review by experienced researchers in your field

- rapid publication on acceptance

- support for research data, including large and complex data types

- gold Open Access which fosters wider collaboration and increased citations

- maximum visibility for your research: over $100 \mathrm{M}$ website views per year

At $\mathrm{BMC}$, research is always in progress.

Learn more biomedcentral.com/submissions 